\title{
Improved antimelanogenesis and antioxidant effects of polysaccharide from Cuscuta chinensis Lam seeds after enzymatic hydrolysis
}

\author{
Zi-Jun Liu, Ya-Lan Wang, Qi-Ling Li and Liu Yang \\ School of Traditional Chinese Medicine, Southern Medical University, Guangzhou, China
}

\begin{abstract}
Cuscuta chinensis polysaccharide (CPS) was extracted using hot water and enzymatically hydrolyzed C. chinensis polysaccharide (ECPS) was produced by the mannase enzymatic hydrolysis process. The purpose of this research was to investigate the antimelanogenic activity of ECPS and CPS in B16F10 melanoma cells. The in vitro antioxidant activity was assessed by their ferric iron reducing power and DPPH free radical scavenging activities. The molecular mass distribution of polysaccharides was determined using SEC-MALLS-RI. CPS was successfully enzymatically degraded using mannase and the weighted average molecular weights of CPS and ECPS were $434.6 \mathrm{kDa}$ and $211.7 \mathrm{kDa}$. The results of biological activity assays suggested that the enzymatically hydrolyzed polysaccharide had superior antimelanogenic activity and antioxidant effect than the original polysaccharide. ECPS exhibited antimelanogenic activity by down-regulating the expression of tyrosinase, MITF, and TRP-1 without cytotoxic effects in B16F10 melanoma cells. In conclusion, ECPS have the potential to become a skin whitening product.
\end{abstract}

Key words: Cuscuta chinensis polysaccharide; Antimelanogenic activity; Enzymatic hydrolysis polysaccharide; Antioxidant activity

\section{Introduction}

Melanin is the L-tyrosine transformation end-product, which is the major determinant of hair and skin color and plays a vital role in protection against ultraviolet radiation injury (1). However, accumulation of melanin might be involved in abnormal pigmentation and result in hyperpigmentation of skin, melasma, solar melanosis, and ephelides (2). Biosynthesis of melanin involves a sequence of enzymatic and oxidative reactions and tyrosinase plays an important role in the process (3). The tyrosinase-related protein (TRP-1) facilitates the formation of DHICA oxidase in melanin biosynthetic pathway (4). Intracellular microphthalmia-associated transcription factor (MITF) is an important transcription regulator of melanin biosynthesis genes. MITF also participates in regulation of melanocyte pigmentation, proliferation, and differentiation (5). $\alpha$-MSH-melanocortin 1 receptor signaling occurs in melanogenic specific enzymes, including TRP-1; tyrosinase is also regulated by the MITF (5). Many skin whitening agents exert the anti-melanogenic effects by regulation of tyrosinase expression or inhibitory effects on tyrosinase activity. Moreover, the intracellular antioxidant level and free radical production also have an effect on melanin content (6). Therefore, tyrosinase inhibitors and antioxidant compounds are often selected as skin whitening agents. Cuscuta chinensis Lam., called TuSiZi in Chinese, is a traditional Chinese medicine generally used as a functional food and known to enhance reproductive system ability (7). In recent years, some reports have indicated its use to treat freckles and vitiligo (8). Other reports have shown that it exerts a positive effect on skin protection (9), and induces the inhibition of tyrosinase activity (10).

Polysaccharides are the main constituents from the water extract of $C$. chinensis Lam. seed, which are considered to have anti-apoptosis (11) and immunological activities (12). Previous analytical results have indicated that $C$. chinensis Lam. polysaccharide is composed of fructose, mannose, xylose, and arabinose; mannose is the main sugar component (13). Many researchers have demonstrated that the viscosity (14), molecular weight (Mw) distributions (15), and monosaccharide proportion (16) of polysaccharides have a great effect on their bioactivity. Moreover, recent research has shown that degraded polysaccharides with low Mw exhibit higher antioxidant and tyrosinase-inhibiting activities than the original polysaccharide (17). Thus, the production of a low Mw

Correspondence: Liu Yang: <yl19801706@163.com> 
polysaccharide from $C$. chinensis Lam. seed is necessary to improve its bioactivity. Among the different degradation processes, the major advantages of enzymatic degradation are the substrate specificity, high selectivity, and mild conditions, which produce hydrolysates with well-defined structures (18).

Based on these pharmacological studies, we speculated that $C$. chinensis polysaccharide (CPS) and enzymatically hydrolyzed $C$. chinensis polysaccharide (ECPS) might be effective botanical drugs for the improvement of hyperpigmentation. Mannase was used to obtain low $\mathrm{Mw}$ ECPS from seed. In addition, the antimelanogenesis and antioxidant activities of polysaccharides with different $\mathrm{Mw}$ were estimated, and the relationship between bioactivities and $\mathrm{Mw}$ of polysaccharides were investigated.

\section{Material and methods}

\section{Reagents}

Chemicals for enzyme and antioxidant activities were purchased from Sigma Co. (USA). All other reagents and chemicals were purchased from Aladdin (China).

\section{Preparation of CPS and ECPS}

The medicinal materials of Cuscuta chinensis Lam seeds were provided from Guang Dong Feng Chun Pharmaceutical CO., LTD (China). About $500 \mathrm{~g}$ dry materials were powdered, and soaked with $1200 \mathrm{~mL} 80 \%$ ethanol for $24 \mathrm{~h}$ under room temperature to remove lipids, oligosaccharides, and colored materials. The pretreated samples were filtrated with cloth, and then the dried residue was extracted with $3000 \mathrm{~mL}$ water at $90^{\circ} \mathrm{C}$ for three times. The aqueous extracts were separated from the residue by centrifugation $\left(4000 \mathrm{~g}\right.$ for $5 \mathrm{~min}$ at $\left.22^{\circ} \mathrm{C}\right)$ and then concentrated at $70^{\circ} \mathrm{C}$ under vacuum; the condensate was precipitated with $60 \%$ ethanol at $3^{\circ} \mathrm{C}$ for $24 \mathrm{~h}$. Finally, the precipitate was deproteinated by the Sevag method, dialyzed with $3500 \mathrm{Da}$ membrane, lyophilized, and then labeled C. chinensis polysaccharide (CPS).

The enzymatically hydrolyzed $C$. chinensis polysaccharide (ECPS) was obtained by hydrolysis with mannase $(0.1 \%$ in sodium acetate buffer) in a mannase to substrate ratio of $5: 1(\mathrm{v} / \mathrm{w})$ at $60^{\circ} \mathrm{C}, \mathrm{pH} 4.5$ for $6 \mathrm{~h}$. Thereafter, the catalysis reaction was terminated in boiling water for $10 \mathrm{~min}$. The reaction solution was centrifuged at $10,000 \mathrm{~g}$ for $15 \mathrm{~min}\left(4^{\circ} \mathrm{C}\right)$, the supernatant was collected for dialysis at $3^{\circ} \mathrm{C}$ for 3 days with a $3500 \mathrm{Da}$ membrane to remove the small molecular substances, and was lyophilized.

The carbohydrate content was tested by the phenolsulfuric acid method with glucose as the standard substance of a calibration curve.

\section{SEC-MALLS-RI measurement}

Size exclusion chromatography (Waters, USA) combined with multi-angle laser light scattering detector (Wyatt, USA) and a refractive index detector (Waters, USA) (SEC-MALLS-RI) were used to detect weighted average molecular weights of polysaccharide. SEC-MALLS-RI was carried out with Phenomenex Polysep-GFC-Linear column $(8 \mathrm{~mm} \times 300 \mathrm{~mm})$; samples $(2 \mathrm{mg} / \mathrm{mL})$ were dissolved with mobile phase, which consisted of $0.1 \mathrm{M}$ sodium chloride. The injection volume was $100 \mu \mathrm{L}$ and flow was set at $0.7 \mathrm{~mL} / \mathrm{min}$.

\section{Mushroom tyrosinase inhibition assay}

Mushroom tyrosinase inhibition (19) was performed as previously reported with modifications. Briefly, $25 \mu \mathrm{L}$ of Kojic acid (positive control) or sample solutions $(25 \mu \mathrm{L}$ of $10 \mathrm{mM}$ L-tyrosine, $25 \mu \mathrm{L}$ of $0.5 \mathrm{mM} \mathrm{L-DOPA}$, and $875 \mu \mathrm{L}$ of $50 \mathrm{mM}$ phosphate buffer ( $\mathrm{pH} 6.5$ ) solution) were mixed. Then, $38 \mu \mathrm{L}$ of $2100 \mathrm{U} / \mathrm{mL}$ mushroom tyrosinase was added and vortexed. After 0.5 -h incubation at $37^{\circ} \mathrm{C}$, the absorbance was measured with a microplate reader at $475 \mathrm{~nm}$ (Thermo Fisher, USA). The inhibition percent of tyrosinase activity was calculated by the following formula: $\%$ tyrosinase inhibition $=\left[\left(A-{ }_{\text {control }}-A-{ }_{\text {sample }}\right) / A-{ }_{\text {control }}\right] \times$ 100 , where $A$-control represents the absorbance at $475 \mathrm{~nm}$ without sample and $A$-sample represents the absorbance at $475 \mathrm{~nm}$ with sample.

\section{Cell culture and viability assay}

Murine B16F10 melanoma cells were purchased from Biochemistry and Cell Biology (China). Cells were maintained in Dulbecco's Modified Eagle Medium (DMEM) supplemented with $10 \%$ fetal bovine serum (FBS), $100 \mu \mathrm{g} / \mathrm{mL}$ streptomycin, and $100 \mathrm{IU} / \mathrm{mL}$ penicillin at $37^{\circ} \mathrm{C}$ in a humidified circumstance containing $5 \% \mathrm{CO}_{2}$. Cells were seeded on culture plates and supplemented with different concentrations of samples and $\alpha$-melanocyte stimulating hormone $(\alpha-\mathrm{MSH})$ for $72 \mathrm{~h}$ to measure the intracellular tyrosinase activity and quantitate melanin contents.

The 3-(4,5-dimethylthiazol-2-yl)-2,5-diphenyltetrazolium bromide (MTT) assay was carried out to test cell viability (20). Briefly, 96-well plates were seeded with murine B16F10 melanoma cells. A volume $50 \mu \mathrm{L}$ of $2 \mathrm{mg} / \mathrm{ml} \mathrm{MTT}$ was transferred into each well after treatment with $100 \mu \mathrm{L}$ of different sample concentrations for $24 \mathrm{~h}$. After 4-h incubation, the reaction was terminated and the dimethyl sulfoxide was added to dissolve the insoluble resultant. Absorbance was measured at $590 \mathrm{~nm}$ with the microplate reader.

\section{Measurement of melanin content}

The detection of melanin content was carried out with the slightly modified method (21). After washing with iced PBS, melanoma cells $\left(2 \times 10^{4}\right.$ cells per well $)$ were seeded in a 96 -well plate and incubated at $37^{\circ} \mathrm{C}$ for $48 \mathrm{~h}$. Then, $100 \mu \mathrm{L} \mathrm{NaOH}(1 \mathrm{~N})$ was added to each well to dissolve melanoma cells at $80^{\circ} \mathrm{C}$ for $30 \mathrm{~min}$. The lysate was centrifuged at $15,000 \mathrm{~g}$ for $15 \mathrm{~min}\left(4^{\circ} \mathrm{C}\right)$. Then, absorbance was measured with the microplate reader at $405 \mathrm{~nm}$. All experiments were carried out in triplicate. 


\section{Intracellular tyrosinase activity assay}

Intracellular tyrosinase activity assay was carried out according to previous literature with minor modification (22). Briefly, melanoma cells were lysed with lysis buffer (1 mM PMSF, 1\% Triton X-100, $20 \mathrm{mM}$ sodium phosphate) by freeze-thawing. After centrifugation of the lysate at $15,000 \mathrm{~g}$ for $10 \mathrm{~min}\left(4^{\circ} \mathrm{C}\right)$, the protein content of the supernatant was determined by a bicinchoninic acid (BCA) assay. The supernatant protein $(10 \mu \mathrm{g})$ was transferred into $100 \mu \mathrm{L}$ of the reaction mixture $(0.1 \% \mathrm{~L}-\mathrm{DOPA}$ and $0.1 \mathrm{M}$ phosphate buffer). After $60 \mathrm{~min}$ incubation at $37^{\circ} \mathrm{C}$, tyrosinase activity was measured with the microplate reader at $450 \mathrm{~nm}$. All the experiments were carried out in triplicate.

\section{Ferric iron reducing power}

The ferric iron reducing power assay was performed according to previously published method with minor modifications (23). The different concentrations of samples (2 $\mathrm{mL}$ ) or Vc (a positive control) were mixed with $2 \mathrm{~mL}$ potassium ferricyanide (1\%,W/V) and $2 \mathrm{~mL}$ phosphate buffer $(0.2 \mathrm{M}, \mathrm{pH} 6.8)$. After incubation at $50^{\circ} \mathrm{C}$ for $30 \mathrm{~min}$, $2 \mathrm{~mL}$ trichloroacetic acid $(10 \%, \mathrm{~W} / \mathrm{V})$ was transferred into the reaction mixture and centrifuged at $4000 \mathrm{~g}$ for $15 \mathrm{~min}\left(22^{\circ} \mathrm{C}\right)$. The supernatant $(2 \mathrm{~mL})$ was mixed with the mixture containing $2 \mathrm{~mL}$ distilled water and $0.4 \mathrm{~mL} \mathrm{FeCl} 3$ $(0.1 \%, W / V)$. After $10 \mathrm{~min}$ incubation at $37^{\circ} \mathrm{C}$, the absorbance was measured with the microplate reader at $700 \mathrm{~nm}$.

\section{DPPH radical-scavenging activity assay}

The DPPH-scavenging activity assay was carried out as previously reported with some modifications (24). Briefly, $2 \mathrm{~mL}$ of the sample were added to $2 \mathrm{~mL} 0.1 \mathrm{mM}$ DPPH solution and vortexed. After $30 \mathrm{~min}$ incubation in the dark, the absorbance was measured with the microplate reader at $517 \mathrm{~nm}$.

\section{Protein expression analysis by western blot}

After treatment with different concentrations of ECPS for $72 \mathrm{~h}$, the cells were washed with PBS and lysed in RIPA buffer $(150 \mathrm{mM} \mathrm{NaCl}$ in $50 \mathrm{mM}$ pH 8.0 Tris- $\mathrm{HCl}$, $0.5 \%$ sodium deoxycholate, $1.0 \%$ nonidet $\mathrm{P}-40$, and $0.1 \%$ sodium dodecyl sulfate). After centrifugation at $10,000 \mathrm{~g}$ for $25 \mathrm{~min}\left(4^{\circ} \mathrm{C}\right)$, the supernatant of lysates was collected. The proteins were subjected to $12 \%$ SDS-PAGE and then transferred to polyvinylidene difluoride membrane. Blocking was carried out in Tris-buffered saline with Tween-20 and $2 \%$ skim milk powder (TBST), and then incubated for $12 \mathrm{~h}$ at $4^{\circ} \mathrm{C}$. The primary antibodies used were: anti$\beta$-actin (1:5000), anti-TRP-1 (1:500), anti-tyrosinase (1:500), and anti-MITF (1:1000). The primary antibodies were removed and the membranes were cleaned twice with TBST. After that, membranes with horseradish peroxidase-conjugated secondary antibody (Santa Cruz, USA) were incubated for $60 \mathrm{~min}$ at room temperature. The protein bands were washed with TBST again and visualized with ECL kit
(Amersham Pharmacia Biotech, USA) using the UVP imaging system (UVP, USA).

\section{Statistical analysis}

All results are reported as means $\pm S D$ and the experiments were replicated three times. Comparisons between groups were estimated using ANOVA followed by Dunnett's test. Single comparisons between two groups were made by Student's $t$-test. All statistical analyses were made using SPSS software (version 16.0). $\mathrm{P}<0.05$ was usually considered to be statistically significant.

\section{Results}

\section{Mw and total polysaccharides of ECPS and CPS}

The total polysaccharide contents of ECPS and CPS measured by phenol-sulfuric acid assay were 89.17 and $90.26 \%$, respectively. Meanwhile, the Mw of ECPS and CPS were measured by SEC-MALLS-RI. The Mw of ECPS was $211.7 \mathrm{kDa}$, which was lower than CPS (434.6 $\mathrm{kDa}$ ). Figure $1 \mathrm{~A}$ shows the relative intensity (RI) for ECPS and CPS; after enzymatic hydrolysis by mannase, the peak retention time of ECPS was longer than that of CPS. As displayed in Figure 1B, the differential weight fractions of polysaccharides were portrayed as the function of molar mass for samples. The molar mass distribution of polysaccharide changed significantly by enzymatic hydrolysis. The differential weight fraction of ECPS in the low Mw

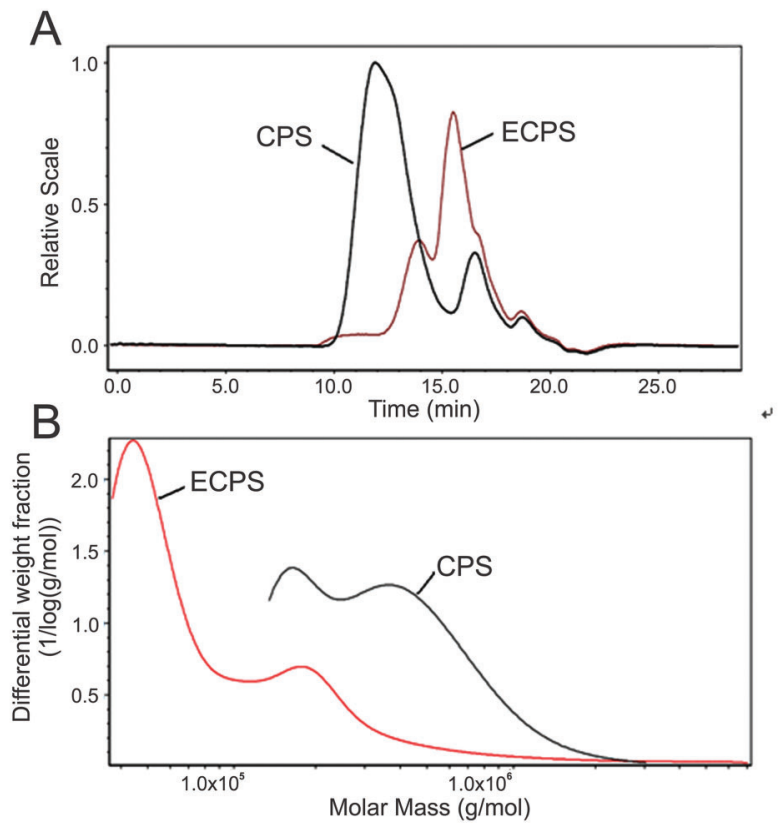

Figure 1. SEC-MALLS-relative intensity result for enzymatically hydrolyzed Cuscuta chinensis polysaccharides (ECPS) and Cuscuta chinensis polysaccharides (CPS) dissolved in $0.1 \mathrm{M}$ sodium chloride solution at $24^{\circ} \mathrm{C}$. $A$, Relative intensity. $B$, Molar mass distribution. 
A
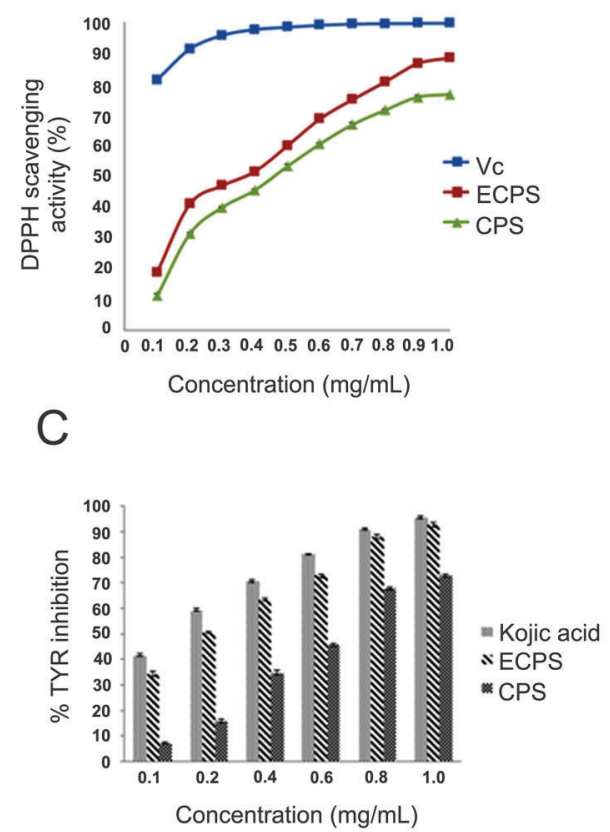

B

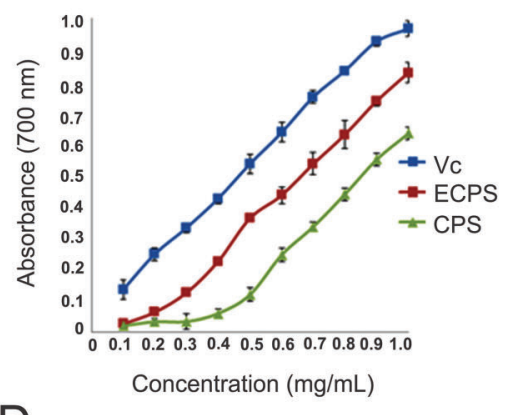

$\mathrm{D}$

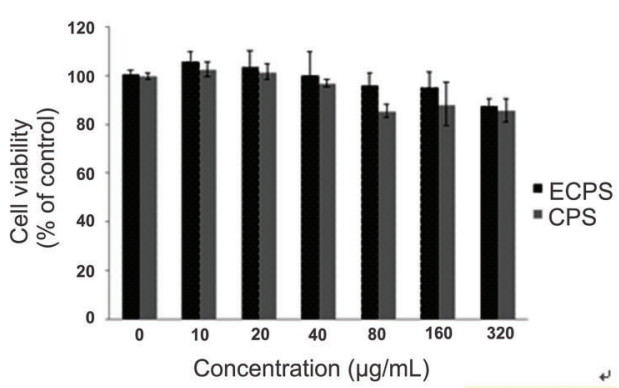

Figure 2. Antioxidant and anti-tyrosinase effects of polysaccharide fragments. $A$, DDPH scavenging activity. $B$, Ferric iron reducing power. $C$, Tyrosinase (TYR) inhibition rates compared with positive control (Kojic acid). D, Effects of ECPS and CPS on B16F10 cells viability. Data are reported as means \pm SD $(n=3)$. ECPS: enzymatically hydrolyzed Cuscuta chinensis polysaccharides; CPD: Cuscuta chinensis polysaccharides; Vc: positive control.

region increased, which suggested that the CPS was enzymatically degraded into low Mw polysaccharide.

\section{Antioxidant activities of polysaccharides}

The DPPH free-radical scavenging abilities of ECPS and CPS are reported in Figure $2 A$. The free-radical scavenging activities of polysaccharide samples and $\mathrm{Vc}$ exhibited a dose-dependent activity. In the current study, the free-radical scavenging ability of CPS was lower than that of ECPS. However, both exhibited lower free-radical scavenging effect than the positive sample. The $\mathrm{IC}_{50}$ values of ECPS and CPS were 0.39 and $0.51 \mathrm{mg} / \mathrm{mL}$, respectively. As displayed in Figure $2 \mathrm{~B}$, the total antioxidant activity can be assessed by testing the ferric iron reducing power. The concentrations varied from 0.1 to $1 \mathrm{mg} / \mathrm{mL}$; both polysaccharide samples and Vc presented antioxidant activity in a dose-dependent manner. Moreover, the absorbance value of ECPS was always higher than that of CPS at the same concentration.

\section{Effect of ECPS and CPS on mushroom tyrosinase activity and cell viability}

As shown in Figure $2 \mathrm{C}$, the tyrosinase inhibitory activity of polysaccharides $(0.1 \sim 1 \mathrm{mg} / \mathrm{mL})$ presented a dose-dependent relationship. Moreover, the inhibitory effect of ECPS was always higher than that of CPS at the same concentration. The MTT assay was performed to assess the cytotoxic effects of ECPS and CPS in B16F10 melanoma cells. As displayed in Figure 2D, there were no significant changes in B16F10 cell viability with different concentrations $(0 \sim 320 \mu \mathrm{g} / \mathrm{mL})$ of ECPS and CPS. Based on these results, we used these concentration ranges in further research.

\section{Effect of ECPS and CPS on intracellular tyrosinase activity and melanin contents}

To compare the effects of ECPS and CPS on the activity of intracellular tyrosinase and melanogenesis in B16F10 melanoma cell model, the inhibitory potency of ECPS and CPS on melanin content and tyrosinase activity in $\alpha-\mathrm{MSH}$-stimulated B16F10 cells were examined. As shown in Figure 3, melanin content and tyrosinase activity of B16F10 cells were significantly increased when compared to the unstimulated B16F10 cells $(P<0.01)$. At concentrations of $40 \mu \mathrm{g} / \mathrm{mL}$ (ECPS) and $160 \mu \mathrm{g} / \mathrm{mL}$ (CPS), the increase of melanin contents could be mitigated in a dose-dependent manner $(P<0.01$ and $P<0.05)$. Similarly, treatment with ECPS $(40 \mu \mathrm{g} / \mathrm{mL})$ and CPS $(160 \mu \mathrm{g} / \mathrm{mL})$ suppressed the tyrosinase activity of B16F10 cells $(P<$ 0.01 and $P<0.05)$. Moreover, ECPS exhibited higher tyrosinase inhibitory activity on melanogenesis than CPS. ECPS (160 and $320 \mu \mathrm{g} / \mathrm{mL}$ ) exerted antimelanogenesis 

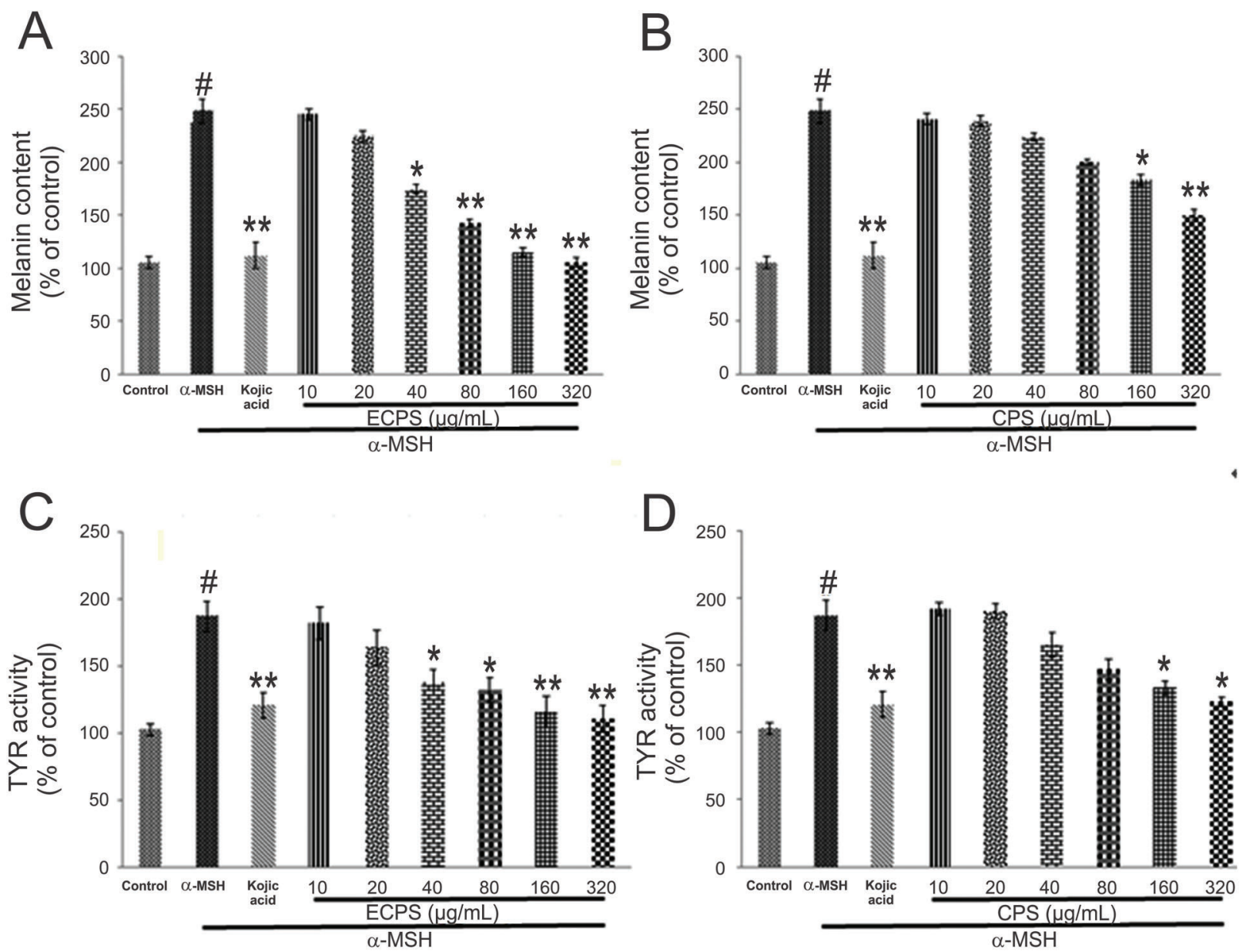

Figure 3. Effects of enzymatically hydrolyzed Cuscuta chinensis polysaccharides (ECPS) and Cuscuta chinensis polysaccharides (CPS) on B16F10 cells. Melanin content and tyrosinase (TYR) activity of melanoma cells were measured after ECPS $(A$ and $C)$ and CPS $(B$ and $D)$ treatment. Kojic acid $(160 \mu \mathrm{g} / \mathrm{mL})$ was used as positive control. Data are reported as means \pm SD. ${ }^{*} \mathrm{P}<0.01 \mathrm{compared}$ to control group; ${ }^{*} \mathrm{P}<0.05$, ${ }^{* *} \mathrm{P}<0.01$ compared to $\alpha$-melanocyte stimulating hormone ( $\alpha-\mathrm{MSH}$ ) group (ANOVA followed by Dunnett's test).

effect comparable to the positive control (Kojic acid), which is widely used as skin whitening bioactive compound.

\section{Effect of ECPS on tyrosinase, MITF, and TRP-1 protein levels in B16F10 cells \\ As shown in Figure 4, the ECPS significantly decreased tyrosinase, MITF, and TRP-1 protein expression levels in B16F10 cells in a dose-dependent manner $(P<0.05$ and $P<0.01)$. These results show that ECPS inhibited the expression of tyrosinase by down-regulating protein expres- sion of TRP-1 and MITF.}

\section{Discussion}

The natural polysaccharides from $C$. chinensis have received attention attributed to the good effects on tyrosinase inhibition, free radical scavenging, and skin protection (25-27). However, little research has focused on the antimelanogenesis activity of enzymatic modification of polysaccharides. Previous research has demonstrated that degraded polysaccharides by enzymatic hydrolysis process exhibited superior free radical scavenging effect (28). Moreover, the biological activities of polysaccharides are closely related to their Mw distributions. Theoretically, low Mw polysaccharides are more active than high Mw polysaccharides due to their high penetration property on cell membranes $(29,30)$. However, the antimelanogenesis effect of ECPS on B16F10 cells had not yet been studied. The low Mw polysaccharide was prepared by enzymatic hydrolysis with mannase.

Oxidative stress can produce excessive free radicals and lead to oxidative injury. Previous studies have proven 
A
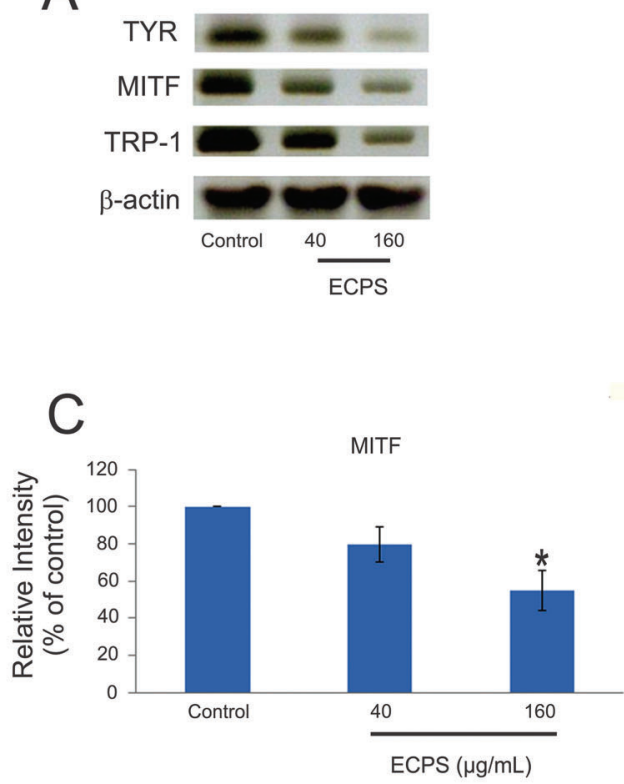
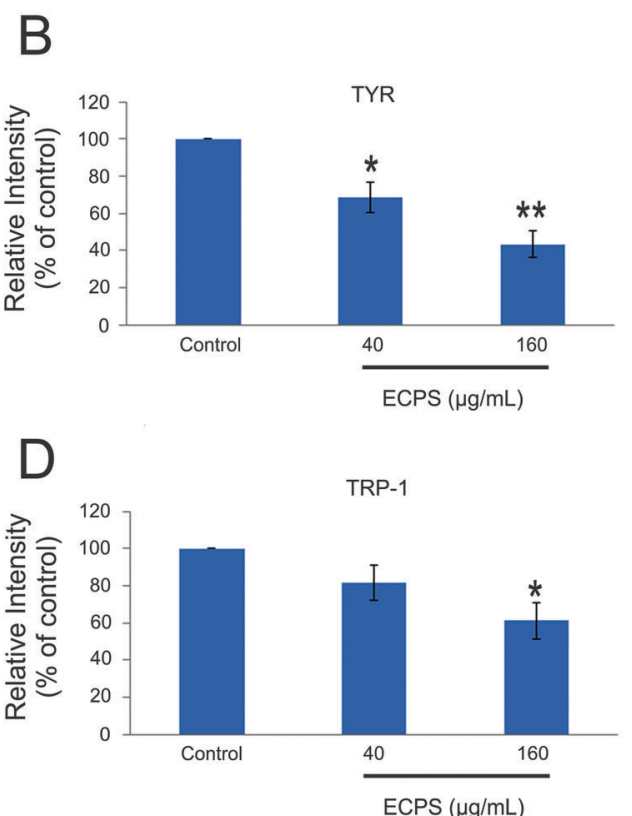

Figure 4. Protein levels of tyrosinase (TYR), microphthalmia-associated transcription factor (MITF) and tyrosinase-related protein (TRP-1) were examined by western blots $(A)$. The ratios of TYP/ $\beta$-actin, MITF/ $\beta$-actin, and TRP- $1 / \beta$-actin are reported in panels $B-D$ as means \pm $\mathrm{SD}$. ${ }^{*} \mathrm{P}<0.05,{ }^{* *} \mathrm{P}<0.01$ compared to control group (ANOVA followed by Dunnett's test). ECPS: enzymatically hydrolyzed Cuscuta chinensis polysaccharides.

that skin disease is closely related to accumulation of free radicals (31). Moreover, excessive free radicals play a vital role in suppressing melanogenesis of melanoma cells and growth of melanocytes (32). Tyrosinase is a multifunctional oxidant enzyme that contains bronze and is vital in promoting melanin biosynthesis (33). However, skin pigmentation and various skin diseases are closely related to the accumulation of melanin and cause a serious esthetic problem (34).

Active ingredients with antioxidant and anti-tyrosinase abilities can exert skin protection and inhibit melanogenesis (35). Our results have demonstrated that the lower Mw of enzymatically modified polysaccharides exhibited superior antioxidant and anti-tyrosinase activities than original polysaccharides in vitro. The improvement is attributed to the greater surface area and better water solubility, which was consistent with a previous study (17) that showed that the degraded polysaccharide from Sargassum fusiforme possesses superior anti-tyrosinase activity and antioxidant activity than the original polysaccharide.

Normal melanocytes lie at the junction of the epidermis and dermis of the skin and generate melanin, which is transferred to keratinocytes (36). In the present study, the murine B16F10 melanoma cells were used because they possess melanogenic mechanism, are known to have intracellular tyrosinase, and can generate melanin, which are related to $\alpha-\mathrm{MSH}$ stimulation and melanogenesis (37).
Tyrosinase activity, melanin content, and cell viability were the in vitro assays used to screen antimelanogenesis in present study. CPS and ECPS exhibited a dose-dependent inhibitory effect on tyrosinase activity and melanin synthesis in B16F10 cells. ECPS showed a stronger anti-melanin synthesis and anti-tyrosinase effect.

Tyrosinase-related protein-1 (TRP-1) and tyrosinase play a vital role in melanin biosynthesis and melanogenesis pathways (38). MITF is a cellular transcription factor of the tyrosinase gene, which takes part in melanogenesis. Usually, the activation of TRP-1 and tyrosinase enhances MITF protein expression and causes the increase of melanin synthesis (39). Thus, skin whitening agents may have the property of inhibiting the signaling pathway involved in the activation of TYP-1 or tyrosinase. Therefore, we investigated the effects of ECPS on TRP-1, cellular tyrosinase and MITF protein expressions to study the mechanisms underlying the inhibition of tyrosinase activity and melanogenesis. The results of western bolt assay showed that ECPS suppressed the expression of TRP-1, tyrosinase, and MITF in B16F10 cells and implied that ECPS decreased melanogenesis by down-regulating tyrosinase, MITF, and TRP-1 expression in B16F10 melanoma cells. The result was in accordance with a previous study showing that the aqueous extract from Cuscuta japonica seed significantly inhibited $\alpha-\mathrm{MSH}$-induced melanin synthesis and tyrosinase activity by suppressing p38 MAPK 
phosphorylation, inhibiting cAMP levels, and subsequently decreasing the expression of TRP and MITF (40).

In summary, the enzymatically modified polysaccharide possessed superior antioxidant and antimelanogenic effects than the original polysaccharide. Furthermore, this antimelanogenic effect of ECPS was mediated by the suppression of TRP-1, tyrosinase, and MITF expression in

\section{References}

1. Riley PA. Melanogenesis and melanoma. Pigment Cell Research 2003; 16: 548-552, doi: 10.1034/j.1600-0749. 2003.00069.x.

2. Ortonne JP, Bissett DL. Latest insights into skin hyperpigmentation. J Investig Dermatol Symp Proc 2008; 13: 10-14, doi: 10.1038/jidsymp.2008.7.

3. Arung ET, Kuspradini H, Kusuma IW, Shimizu K, Kondo R. Validation of Eupatorium triplinerve Vahl leaves, a skin care herb from East Kalimantan, Using a Melanin Biosynthesis Assay. J Acupunct Meridian Stud 2012; 5: 87-92, doi: 10.1016/ j.jams.2012.01.003.

4. Kobayashi T, Urabe K, Winder A, Jiménez-Cervantes C, Imokawa $\mathrm{G}$, Brewington $\mathrm{T}$, et al. Tyrosinase related protein 1 (TRP1) functions as a DHICA oxidase in melanin biosynthesis. EMBO J 1994; 13: 5818-5825.

5. Costin GE, Hearing VJ. Human skin pigmentation: melanocytes modulate skin color in response to stress. FASEB $J$ 2007; 21: 976-994, doi: 10.1096/fj.06-6649rev.

6. Galván I, Alonso-Alvarez C. An Intracellular antioxidant determines the expression of a melanin-based signal in a bird. PLoS One 2008; 3: e3335, doi: 10.1371/journal.pone. 0003335.

7. Yang J, Wang Y, Bao Y, Guo J. The total flavones from Semen cuscutae reverse the reduction of testosterone level and the expression of androgen receptor gene in kidneyyang deficient mice. J Ethnopharmacol 2008; 119: 166-171, doi: 10.1016/j.jep.2008.06.027.

8. Donnapee S, Li J, Yang X, Ge AH, Donkor PO, Gao XM, et al. Cuscuta chinensis Lam.: A systematic review on ethnopharmacology, phytochemistry and pharmacology of an important traditional herbal medicine. J Ethnopharmacol 2014; 157: 292-308, doi: 10.1016/j.jep.2014.09.032.

9. Nisa M, Akbar S, Tariq M, Hussain Z. Effect of Cuscuta chinensis water extract on 7,12-dimethylbenz[a]anthraceneinduced skin papillomas and carcinomas in mice. J Ethnopharmacol 1986; 18: 21-31, doi: 10.1016/0378-8741(86)90040-1.

10. Wang TJ, An J, Chen XH, Deng QD, Yang L. Assessment of Cuscuta chinensis seeds' effect on melanogenesis: Comparison of water and ethanol fractions in vitro and in vivo. J Ethnopharmacol 2014; 154: 240-248, doi: 10.1016/j.jep. 2014.04.016.

11. Sun SL, Guo L, Ren YC, Wang B, Li RH, Qi YS, et al. Antiapoptosis effect of polysaccharide isolated from the seeds of Cuscuta chinensis Lam on cardiomyocytes in aging rats. Mol Biol Rep 2014; 41: 6117-6124, doi: 10.1007/s11033014-3490-1.

12. Wang Z, Fang JN, Ge DL, Li XY. Chemical characterization and immunological activities of an acidic polysaccharide isolated from the seeds of Cuscuta chinensis Lam. Acta Pharmacol Sin 2000; 21: 1136-1140. murine B16F10 cells. ECPS can be applicable for use in the fields of cosmetic and medicine products.

\section{Acknowledgements}

This work was supported by the National Natural Science Foundation of China (grant No. 81373640).

13. Yang $S, X u X, X u H, X u S$, Lin Q, Jia Z, et al. Purification, characterization and biological effect of reversing the kidneyyang deficiency of polysaccharides from Semen cuscutae. Carbohydr Polym 2017; 175: 249-256, doi: 10.1016/j.carbpol. 2017.07.077.

14. Katayama S, Nishio T, Kishimura H, Saeki H. Immunomodulatory properties of highly viscous polysaccharide extract from the Gagome alga (Kjellmaniella crassifolia). Plant Food Humn Nutr 2012; 67: 76-81, doi: 10.1007/s11130-0110271-z.

15. Pengzhan Y, Ning L, Xiguang L, Gefei Z, Quanbin Z, Pengcheng L. Antihyperlipidemic effects of different molecular weight sulfated polysaccharides from Ulva pertusa (Chlorophyta). Pharmacol Res 2003; 48: 543-549, doi: 10.1016/ S1043-6618(03)00215-9.

16. Jiang Y, Qi X, Gao K, Liu W, Li N, Cheng N, et al. Relationship between molecular weight, monosaccharide composition and immunobiologic activity of Astragalus polysaccharides. Glycoconj J 2016; 33: 755-761, doi: 10.1007/ s10719-016-9669-z.

17. Chen BJ, Shi MJ, Cui S, Hao SX, Hider RC, Zhou T. Improved antioxidant and anti-tyrosinase activity of polysaccharide from Sargassum fusiforme by degradation. Int $J$ Biol Macromol 2016; 92: 715-722, doi: 10.1016/j.ijbiomac. 2016.07.082.

18. McCleary BV. Enzymatic modification of plant polysaccharides. Int J Biol Macromol 1986; 8: 349-354, doi: 10.1016/ 0141-8130(86)90054-1.

19. Baurin N, Arnoult E, Scior T, Do QT, Bernard P. Preliminary screening of some tropical plants for anti-tyrosinase activity. J Ethnopharmacol 2002; 82: 155-158, doi: 10.1016/S03788741(02)00174-5.

20. Mosmann T. Rapid colorimetric assay for cellular growth and survival: Application to proliferation and cytotoxicity assays. J Immunol Methods 1983; 65: 55-63, doi: 10.1016/00221759(83)90303-4.

21. Hosoi J, Abe E, Suda T, Kuroki T. Regulation of melanin synthesis of B16 mouse melanoma cells by 1 alpha, 25-dihydroxyvitamin D3 and retinoic acid. Cancer Res 1985; 45: 1474-1478.

22. Wang $\mathrm{HM}$, Chen $\mathrm{CY}$, Wen $\mathrm{ZH}$. Identifying melanogenesis inhibitors from Cinnamomum subavenium with in vitro and in vivo screening systems by targeting the human tyrosinase. Exp Dermatol 2011; 20: 242-248, doi: 10.1111/j.1600-0625. 2010.01161.x.

23. Berker KI, Güçlü K, Tor I, Apak R. Comparative evaluation of $\mathrm{Fe}(\mathrm{III})$ reducing power-based antioxidant capacity assays in the presence of phenanthroline, batho-phenanthroline, tripyridyltriazine (FRAP), and ferricyanide reagents. Talanta 2007; 72: 1157-1165, doi: 10.1016/j.talanta.2007.01.019. 
24. Parejo I, Codina C, Petrakis C, Kefalas P. Evaluation of scavenging activity assessed by $\mathrm{Co}(\mathrm{II}) / \mathrm{EDTA}$-induced luminol chemiluminescence and DPPH · (2,2-diphenyl-1-picrylhydrazyl) free radical assay. J Pharmacol Toxicol Methods 2000; 44: 507-512, doi: 10.1016/S1056-8719(01)00110-1.

25. Rout S, Banerjee R. Free radical scavenging, anti-glycation and tyrosinase inhibition properties of a polysaccharide fraction isolated from the rind from Punica granatum. Bioresour Technol 2007; 98: 3159-3163, doi: 10.1016/j.biortech.2006. 10.011.

26. $\mathrm{Yu} P$ and Sun $\mathrm{H}$. Purification of a fucoidan from kelp polysaccharide and its inhibitory kinetics for tyrosinase. Carbohydrate Polymers 2014; 99: 278-283, doi: 10.1016/ j.carbpol.2013.08.033.

27. Wei X, Liu Y, Xiao J, Wang Y. Protective effects of tea polysaccharides and polyphenols on skin. J Agric Food Chem 2009; 57: 7757-7762, doi: 10.1021/jf901340f.

28. Xu J, Xu LL, Zhou QW, Hao SX, Zhou T, Xie HJ. Enhanced in vitro antioxidant activity of polysaccharides from Enteromorpha prolifera by enzymatic degradation. J Food Biochem 2016; 40: 275-283, doi: 10.1111/jfbc.12218.

29. Zhou J, Hu N, Wu YI, Pan Yj, Sun CR. Preliminary studies on the chemical characterization and antioxidant properties of acidic polysaccharides from Sargassum fusiforme. J Zhejiang Univ Sci B 2008; 9: 721-727, doi: 10.1631/jzus. B0820025.

30. Wu Q, Zheng C, Ning ZX, Yang B. Modification of low molecular weight polysaccharides from Tremella fuciformis and their antioxidant activity in vitro. Int $\mathrm{J} \mathrm{Mol} \mathrm{Sci} \mathrm{2007;} \mathrm{8:}$ 670-679, doi: 10.3390/i8070670.

31. Yasui $H$, Sakurai $H$. Age-dependent generation of reactive oxygen species in the skin of live hairless rats exposed to UVA light. Exp Dermatol 2003; 12: 655-661, doi: 10.1034/ j.1600-0625.2003.00033.x.

32. Yamakoshi J, Otsuka F, Sano A, Tokutake S, Saito M, Kikuchi M, et al. Lightening effect on ultraviolet-induced pigmentation of guinea pig skin by oral administration of a proanthocyanidin-rich extract from grape seeds. Pigment Cell Res 2003; 16: 629-638, doi: 10.1046/j.1600-0749. 2003.00093.x

33. Strothkamp KG, Jolley RL, Mason HS. Quaternary structure of mushroom tyrosinase. Biochem Biophys Res Commun 1976; 70: 519-524, doi: 10.1016/0006-291X(76)91077-9.

34. Parvez S, Kang M, Chung HS, Bae H. Naturally occurring tyrosinase inhibitors: mechanism and applications in skin health, cosmetics and agriculture industries. Phytother Res 2007; 21: 805-816, doi: 10.1002/ptr.2184.

35. Perluigi M, De Marco F, Foppoli C, Coccia R, Blarzino C, Luisa Marcante $\mathrm{M}$, et al. Tyrosinase protects human melanocytes from ROS-generating compounds. Biochem Biophys Res Commun 2003; 305: 250-256, doi: 10.1016/S0006291X(03)00751-4.

36. Hirobe T. How are proliferation and differentiation of melanocytes regulated? Pigment Cell Melanoma Res 2011; 24 : 462-478, doi: 10.1111/j.1755-148X.2011.00845.x.

37. Buscà R, Ballotti R. Cyclic AMP a key messenger in the regulation of skin pigmentation. Pigment Cell Res 2000; 13 : 60-69, doi: 10.1034/j.1600-0749.2000.130203.x

38. Slominski A, Tobin DJ, Shibahara S, Wortsman J. Melanin pigmentation in mammalian skin and its hormonal regulation. Physiol Rev 2004; 84: 1155-1228, doi: 10.1152/physrev. 00044.2003

39. Shibahara S, Yasumoto K-I, Amae S, Udono T, Watanabe $\mathrm{K}-\mathrm{I}$, Saito $\mathrm{H}$, et al. Regulation of pigment cell-specific gene expression by MITF. Pigment Cell Res 2000; 13: 98-102, doi: 10.1034/j.1600-0749.13.s8.18.x.

40. Jang JY, Kim HN, Kim YR, Choi YH, Kim BW, Shin HK, et al. Aqueous fraction from Cuscuta japonica seed suppresses melanin synthesis through inhibition of the p38 mitogenactivated protein kinase signaling pathway in B16F10 cells. $J$ Ethnopharmacol 2012; 141: 338-344, doi: 10.1016/j.jep. 2012.02 .043$. 